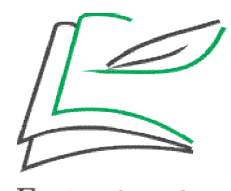

Entretextos

Entretextos 20(2):121-144; jul./dez. 2020

ISSN $1519-5392$

DOI: $10.5433 / 1519-5392.2020 v 21 \mathrm{n} 2 \mathrm{p} 121$

\title{
Reframing empático na formação de professores de inglês nos anos iniciais
}

\author{
Reframing empático en la formación de profesores de inglés en los años \\ iniciales
}

Empathic reframing in the English teacher education for early years

Déborah Caroline Cardoso Pereira ${ }^{1}$ (D) https://orcid.org/0000-0002-7221-840X

\begin{abstract}
RESUMO: O ensino de língua inglesa para crianças (LIC) é realidade nas redes públicas e particulares de ensino. Por outro lado, as lacunas existentes na formação docente, pela falta de diretrizes para este ensino e inclusão desta língua como disciplina da grade curricular comum nas escolas, perpetuam incertezas e desafios quanto às suas práticas em sala de aula. Com vistas a contribuir com a formação inicial de professores/as que atuam com o ensino de LIC nas escolas municipais de Apucarana (PR), foi desenvolvido um projeto de extensão na Universidade Estadual do Paraná (Unespar) o qual almejava promover práticas críticas de ensino-aprendizagem de LIC. O objetivo geral deste estudo é compartilhar o sentido de ensino crítico de LIC enquanto momentos críticos (PENNYCOOK, 2001, 2004) que desencadeiam reframing empático (SMAGORINSKY; JHONSON, 2017) desenvolvido e mapeado no projeto em questão. Para isso, foram utilizados os pressupostos Vygotskianos acerca do desenvolvimento conceitual, bem como a teoria da argumentação segundo Liberali (2013). Os resultados indicam que mesmo em nível de pseudoconceito (VYGOTSKY, 2007, 2008) o projeto propiciou o desenvolvimento do reframing empático, capaz de contribuir com uma sociedade mais humana a partir da sala de aula.
\end{abstract}

PALAVRAS-CHAVE: Formação docente crítica. Desenvolvimento conceitual. Ensino de Inglês para crianças. Reframing empático.

ABSTRACT: English language teaching to children (ELTC) is a reality in public and private schools. On the other hand, the existing gaps in teacher education, due to the lack of guidelines for this teaching and the inclusion of this language as a discipline in the common curriculum in schools, perpetuate uncertainties and challenges regarding classroom practices. In order to contribute to the initial education of teachers who work with ELTC in the municipal schools of Apucarana (PR), an extension project was developed at the State University of Paraná (Unespar) which aimed to promote critical practices in the ELTC. The general objective of this study is to share the sense of critical teaching of ELTC as critical moments (PENNYCOOK, 2001, 2004) that trigger empathic reframing (SMAGORINSKY; JHONSON, 2017) developed and

${ }^{1}$ Doutora em Estudos da Linguagem pela Universidade Estadual de Londrina (UEL). Docente nesta mesma Universidade. E-mail: deborahccp@hotmail.com 
mapped in the project in question. For this, Vygotskian assumptions about conceptual development were used, as well as the theory of argumentation according to Liberali (2013). The results indicate that even at the level of a pseudoconcept (VYGOTSKY, 2007, 2008) the project led to the development of empathic reframing, capable of contributing to a more humane society from the classroom.

KEYWORDS: Critical teacher education. Conceptual development. Teaching English to children. Empathic reframing.

RESUMEN: La enseñanza de lengua inglesa para niños es realidad en las redes públicas y particulares de enseñanza. Por otro lado, los fallos existentes en la formación docente, por la falta de directrices para esta enseñanza e inclusión de esta lengua como asignatura del currículum común en las escuelas, perpetúan inseguridades y desafíos en lo que concierne a su práctica en la sala de clase. Con el propósito de contribuir con la formación inicial de profesores/as que actúan con la enseñanza de LI para niños en las escuelas municipales de Apucarana (PR), fue desarrollado un proyecto de extensión en la Universidad Estadual de Paraná (Unespar) en el cual se anhelaba promover prácticas críticas de enseñanza-aprendizaje de LI en los años iniciales. El objetivo general de este estudio es compartir el sentido de enseñanza crítica de LI para niños como momentos críticos (PENNYCOOK, 2001, 2004) que desencadenan reframing empático (SMAGORINSKY; JHONSON, 2017) desarrollado y mapeado en el proyecto en cuestión. Para tanto, fueron utilizados los presupuestos Vygotskianos acerca del desarrollo conceptual, así como la teoría de la argumentación según Liberali (2013). Los resultados indican que, aunque en nivel de pseudoconcepto (VYGOTSKY, 2007, 2008), el proyecto propició el desarrollo de reframing empático, capaz de contribuir con una sociedad más humana a partir de la sala de clase.

PALABRAS CLAVE: Formación docente crítica. Desarrollo conceptual. Enseñanza de Inglés para niños. Reframing empático.

\section{Introdução}

No atual cenário político educacional brasileiro, a educação infantil e o ensino nas séries iniciais estão sob responsabilidade dos governos municipais. Assim, cabe às prefeituras ofertar e regulamentar este ensino. No que tange ao ensino de línguas estrangeiras, temos sua não obrigatoriedade, ao passo que a oferta do ensino de Língua Inglesa para Crianças (LIC) se encontra consolidada no Brasil (majoritariamente nas redes particulares de ensino).

Para atuar neste nicho educacional, observamos, de um lado, as Diretrizes Curriculares Nacionais (1996) defendendo que o/a professor/a tenha formação na língua específica (graduação em Letras); do outro, os/as profissionais graduados/as em Letras que não possuem formação para atuarem com crianças, pois, à princípio, o/a profissional preparado/a para isso é o/a pedagogo/a.

Diante deste cenário, desenvolvi um projeto de formação inicial de professores/as na Universidade Estadual do Paraná (Unespar), cujo enfoque era trabalhar com perspectivas críticas de ensino e aprendizagem de LIC e a formação docente. Este artigo, 
portanto, tem como objetivo compartilhar o sentido de ensino crítico de LIC enquanto momentos críticos (PENNYCOOK, 2001, 2004) que desencadeiam reframing empático (SMAGORINSKY; JHONSON, 2017) desenvolvido no projeto em questão . Para isso, adotei o referencial Vygotskiano (VYGOTSKY, 2007, 2008), com o fim de analisar o desenvolvimento dos conceitos manipulados no grupo e a teoria da argumentação, segundo Liberali (2013).

Este artigo está dividido em quatro partes. Na primeira, discuto os momentos críticos, o desenvolvimento conceitual e o reframing empático, na sequência, a metodologia seguida da discussão dos resultados permeada pelos pressupostos teóricometodológicos e, logo após, algumas considerações finais.

\section{Momentos Críticos que Desencadeiam Reframing Empático}

Em oposição às metodologias tradicionais de formação e ensino de línguas estrangeiras, diferentes alternativas têm sido desenvolvidas, tais como: pedagogia decolonial, abordagem reflexiva, perspectivas críticas. Pennycook (2001, 2004), por sua vez, investiga práticas críticas a partir de momentos críticos. Para o pesquisador, a noção de crítico requer problematizar a prática, levantando questões de língua, discurso, poder e identidade. Esta visão é auto-reflexiva e reflete sobre a própria linguística aplicada (PENNYCOOK, 2001). Inseridos nesta perspectiva de prática problematizadora estão os momentos críticos que são fundamentais para a organização e análise de dados deste estudo. Segundo Pennycook (2004, p. 330):

Há um outro sentido da noção de crítico que também parece importante: crítico como em um momento crítico, um ponto de importância, um instante em que as coisas mudam. Parece-me que na supervisão de estágio e, pensando melhor, na nossa prática docente de maneira geral, é isto que estamos buscando: aqueles momentos quando aproveitamos a oportunidade para fazer algo diferente, quando percebemos que estamos desenvolvendo um novo entendimento. Isto é talvez uma noção negligenciada em abordagens de ensino, discussões em formação de professores, e abordagens críticas de educação. É talvez inevitável que olhemos para a educação em termos de ementa (leituras, material do curso) e ao currículo mais amplo (metodologia de ensino, tarefas, discussões, atividades). Mas como capturamos aqueles momentos críticos quando alguma coisa muda, onde alguém "percebe", onde alguém faz um comentário que muda o discurso? Uma questão difícil para todos os professores é como conseguir capturar aqueles momentos de transformações em potencial e torná-los em momentos críticos em ambos sentidos. 
Os momentos críticos são, portanto, momentos inesperados. Trabalhar com assuntos polêmicos e/ou discussões desses temas não compõem momentos críticos, mas a consequência dessas atividades pode se tornar um momento crítico. Como afirma o autor, parece natural aos/às professores/as a preocupação com o currículo, o material, o cronograma, o conteúdo. Talvez, por esta razão, busquemos por metodologias e abordagens de ensino crítico, isto é, algo, através do qual, consigamos nortear essa nova prática. No entanto, durante as aulas, circunstâncias inesperadas acontecem e podem culminar em oportunidades de transformação, com um potencial emancipatório e crítico ainda maior do que textos, materiais, livros e assuntos pré-estabelecidos para esse fim.

Por outro lado, um momento crítico pode não ser explorado pelos/as professores/as em sala de aula ou, ainda que levantados, podem não culminar na (transform)ação para um agir mais empático. Segundo Smagorinsky e Johnson (2017), para que consigamos desenvolver um conceito, como o conceito de ensino crítico de LIC, é necessário que nos atentemos aos conceitos sociais e à empatia:

[p]ara que os conceitos sociais se desenvolvam, os entendimentos sociais devem emergir, e estes geralmente têm uma dimensão empática. Esse aspecto do pensamento pode ser cultivado na formação de professores universitários quando as salas de aula são construídas para incluir deliberadamente o envolvimento com as pessoas, seja em textos ou pessoalmente, cujas vidas informam os conceitos em desenvolvimento de maneira frutífera e sensível (SMAGORINSKY; JOHNSON, 2017, p. 31-32, tradução nossa).

Tal processo de desenvolvimento de conceitos é discutido por Vygotsky. O pesquisador investigava o modo com que as pessoas constroem conceitos por meio da atribuição de sentido às palavras a partir de um engajamento cultural (SMAGORINSKY, 2013).

Para Vygotsky, a aprendizagem informal, que ocorre por meio de experiências e contatos sociais, culmina no desenvolvimento dos chamados conceitos cotidianos ou espontâneos. Por conseguinte, o conhecimento aprendido em contextos formais, voltados para a formação específica e teórica, é nomeado conceito científico. Já um conceito, de maneira geral:

"É mais do que a soma de certas conexões associativas formadas pela memória, é mais do que um simples hábito mental; é um ato real e complexo de pensamento que não pode ser ensinado por meio de treinamento" (VYGOTSKY, 2008, p. 104). 
Dito de outra maneira, conceitos não podem ser transferidos de um para o outro, como na chamada educação bancária (FREIRE, 1987), segundo a qual o professor "deposita" o conhecimento em seus alunos. Conceitos implicam no desenvolvimento de funções intelectuais, tais como "atenção deliberada, memória, lógica, abstração, capacidade de comparar e diferenciar" (VYGOTSKY, 2008, p. 104).

Vygotsky (2008) identifica ainda dois tipos de fases básicas na trajetória até a formação de conceitos, visto que ainda não atingem uma unidade teórica: complexos e pseudoconceitos. Ambos dizem respeito aos conceitos científicos e espontâneos.

No estágio de desenvolvimento do entendimento complexo, "objetos isolados associam-se na mente" (VYGOTSKY, 2008, p. 76), ou seja, alguns membros de determinada organização podem estar unificados com outros, mas não estão unificados de acordo com o mesmo princípio. A exemplo da criança que identifica tudo que voa como um inseto, até mesmo um avião (SMAGORINSKY, 2013), ou aquela que identifica todo animal de quatro patas como um cachorro (SMAGORINSKY; COOK; JOHNSON, 2003).

E a forma mais elevada de um complexo no desenvolvimento conceitual (VYGOTSKY, 2008) é nomeada pseudoconceito. Nesta fase, os membros de um conjunto aparecem unificados, mas possuem inconsistências internas. Smagorinsky (2013) usa a metáfora de Vygotsky para explicar que um pseudoconceito é a sombra de um conceito, pois já apresenta seus contornos. Os elementos de um determinado grupo parecem estar unidos, mas há contradições, como as crianças que identificam um cachorro e depois pensam que outros animais a ele semelhantes também pertencem a mesma espécie (SMAGORINSKY; COOK; JOHNSON, 2003).

Já os conceitos sociais são ainda mais complexos de se desenvolverem e de serem investigados, pois contam com a contribuição de fontes espontâneas e científicas, como também a empatia com outro, inclusive, neste contexto específico de formação docente (SMAGORINSKY; JOHNSON, 2017). É pelo envolvimento com as experiências subjetivas (a própria vida) que desenvolvemos esses conceitos. Por fim, Smagorinsky e Johnson (2017) definem reframing empático ao:

[...] que se refere a uma ocasião em que, ao fazer uma conexão emocional com uma situação pessoal direta ou indiretamente de uma pessoa com diferentes experiências de vida, uma pessoa ou um grupo de pessoas muda as perspectivas para ver "o outro" como mais humano e com necessidade de compreensão e simpatia (SMAGORINSKY; JOHNSON, 2017, p. 6, tradução nossa). 
Ou seja, não há somente "aquele momento crítico quando alguma coisa muda" (PENNYCOOK, 2004, p. 330), mas também uma "uma conexão emocional" (SMAGORINSKY; JOHNSON, 2017, p. 6) que faz com que mudemos de perspectiva em relação ao outro.

\section{Metodologia}

Ao atuar como professora colaboradora, desenvolvi um projeto de formação inicial de professores na Universidade Estadual do Paraná (Unespar), intitulado Teaching to play or playing to teach? Juntamente com cinco acadêmicos do curso de Letras-Inglês (Joana, Isabel, João, Nicolas e Catarina ), que lecionavam inglês nas séries iniciais do ensino fundamental, no Município de Apucarana-PR, trabalhamos com perspectivas críticas de ensino e aprendizagem de LIC.

Nosso objetivo era desenvolver práticas críticas no ensino de LIC. Para isso, os encontros do projeto eram embasados em leituras de textos que abordassem teorias crítico-colaborativas de formação docente e do processo de ensino-aprendizagem de inglês para crianças. Inicialmente, eles foram divididos em duas etapas: primeiro, os/as professores/as em formação apresentavam o levantamento semanal de suas aulas (possíveis dilemas, efetividade das atividades, situações da sala de aula, conflitos, soluções), uma vez que a formação crítico-colaborativa parte do pressuposto da necessidade do diálogo, do questionamento, da argumentação, do crescimento junto com o outro, por isso a importância deste momento.

Em um segundo momento, fazíamos discussões dos textos acadêmicos. Em cada encontro, um membro do grupo era responsável pela seleção do material que seria lido e pela condução da discussão, pois na formação colaborativa, além dos papéis e responsabilidades serem intercambiáveis (MATEUS; EL KADRI; SILVA, 2013), é a partir da interação com o outro que compreendemos e constituímos a nós mesmos (MATEUS, 2011).

Esses encontros tiveram início no dia 19 de abril de 2016, no começo do ano letivo (devido à greve no ano anterior, o calendário encontrava-se atípico), e encerraram-se no dia 30 de agosto deste mesmo ano, dado ao início do estágio obrigatório, o desenvolvimento do trabalho de conclusão do curso e uma nova greve. No total, realizamos treze encontros que foram gravados em áudio e transcritos, gerando 
trezentas e quarenta e quatro páginas de transcrições. Cada encontro durava uma hora e meia e acontecia no campus da Unespar.

Incialmente, realizei uma análise de conteúdo (BARDIN, 2006) comparativa (MISSISSIPI STATE UNIVERSITY, 2011), a fim de delimitar um recorte dos dados gravados e transcritos. Fiz uma leitura geral das transcrições, como uma pré-análise desses dados. Depois, realizei a exploração desse material, identificando tópicos que pudessem servir como indicadores para a investigação, dando origem às primeiras possíveis categorias de interpretação, como proposta da análise de conteúdo (BARDIN, 2006).

Em seguida, procurei identificar se os tópicos eram recorrentes por meio de uma análise comparativa (MISSISSIPI STATE UNIVERSITY, 2011) entre as transcrições de cada encontro do projeto. A análise comparativa constitui em manter uma comparação paralela entre similaridades e/ou diferenças em textos. É necessário, inicialmente, estabelecer bases de comparações (MISSISSIPI STATE UNIVERSITY, 2011), daí a relevância de fazê-lo depois do levantamento de tópicos por meio da análise de conteúdo (BARDIN, 2006).

Assim, percebi a reincidência de diferentes noções de ensino crítico de LIC e categorizei meus dados a partir desses relatos de tentativas de ensino crítico realizadas durante as aulas nas escolas municipais, bem como do entendimento dessa perspectiva pelo/no grupo.

Realizado este recorte dos dados, iniciei uma análise colaborativa dos dados com o Prof. Dr. Smagorinsky. Juntos, analisamos sistematicamente os recortes usando o ATLAS.ti , um software de análise de dados de pesquisas qualitativas. Este processo é chamado de codificação dos dados. Após lermos e discutirmos todos os excertos selecionados "chegamos a um acordo sobre cada código por meio de discussão colaborativa ao invés de corroboração independente" (SMAGORINSKY, 2008, p. 401, tradução nossa).

Elencamos os conceitos utilizados pelos/as professores/as em formação na tentativa de formularem o conceito de ensino crítico de LIC (a exemplo a utilização do conceito racismo) e também suas fontes conceituais; se eram espontâneos, científicos ou espontâneo-científicos (como o conceito de racismo que era desenvolvido por meio das práticas em sala de aula, portanto, genuinamente espontâneo). Assim, tínhamos dois focos: os conceitos e suas fontes. 
Tendo em vista que "a codificação torna evidente a abordagem teórica utilizada para analisar os dados aplicando nomes de código aos segmentos de texto" (SMAGORINSKY, 2008, p. 399, tradução nossa), nomeamos todos os códigos inicialmente como conceitos e os subcódigos como as noções de ensino crítico de LIC.

Assim, cada fala era destacada, analisada e categorizada. Escrevíamos os códigos e subcódigos que colaborativamente criávamos, almejando compreender quais conceitos estavam pautando as discussões do grupo, bem como suas fontes (científico, espontâneo ou espontâneo-científico). Para cada fala, desenvolvíamos um ou mais códigos; cada código possuía 3 ou 4 subcódigos, dependendo de sua natureza. Por exemplo, na minha fala (enquanto participante do projeto): "É, porque isso é uma coisa [...] eu já li muitos textos sobre isso, gente. De professor, professora, quanto pela opção sexual quanto, por exemplo, divorciado, sei lá, qualquer coisa. A gente sabe que criança [...]" Nós extraímos 5 códigos diferentes.

O primeiro código: conceito - desenvolvimento - científico - pesquisa, é composto por quatro subcódigos, a saber: i) conceito (como já dito, todos os códigos começavam com o termo conceito, visto que este era o foco da análise); ii) desenvolvimento (quando aquela fala representava a fonte de um conceito e não o conceito em si); iii) científico (natureza do conceito); iv) pesquisas (origem daquele conhecimento).

Os códigos poderiam possuir apenas três subcódigos, representando, assim, um conceito em si, qual seja: i) conceito; ii) percepção dos pais sobre os professores, e o subcódigo que dá sentido ao conceito, neste caso: iii) orientação sexual. Isto quer dizer que os códigos com quatro subcódigos representam a fonte conceitual (espontâneo, científico ou espontâneo-científico) e os códigos com três subcódigos representam um conceito em formação.

Depois de discutirmos e analisarmos todos os excertos, foi "necessária uma redução maior dos dados" (SMAGORINSKY, 2008, p. 406, tradução nossa). Para isso, coletamos todos os códigos criados na plataforma ATLAS.ti, transferimo-los para um documento Word e, assim,

[...] continuamos discutindo quais códigos permaneciam relevantes para o foco do estudo, quais não eram, quais precisavam ser agrupados em categorias únicas, quais precisavam ser renomeados, e tomamos outras decisões que contribuíram para um estudo bem documentado e focado (SMAGORINSKY, 2008, p. 406, tradução nossa). 
Assim, chegamos a cinco grandes conceitos em desenvolvimento durante 0 processo de formação do conceito de ensino crítico nos encontros do projeto, como ilustrado adiante:

Quadro 1 - Conceitos e subcódigos do desenvolvimento conceitual

\begin{tabular}{|c|c|}
\hline CONCEITO & Ocorrências \\
\hline Agir docente $-34 \%$ & 32 \\
\hline Professores podem prevenir ou perpetuar estereótipos e intolerância & 8 \\
\hline Trabalho crítico de um professor pode ser desfeito por outro professor conservador. & 7 \\
\hline Respeito deveria ser mútuo entre professores e alunos. & 5 \\
\hline Poder dos/as professores/as em relação aos alunos. & 4 \\
\hline Ensino crítico não é prioridade na grade escolar. & 2 \\
\hline Professores podem mudar a vida dos alunos. & 2 \\
\hline Professores são exemplos para seus alunos. & 2 \\
\hline Professores podem usar poder para contestar poder. & 1 \\
\hline Professores promovem justiça ao conhecerem as realidades de seus alunos. & 1 \\
\hline LGBTQ+ inclusão/exclusão - 26\% & 24 \\
\hline $\begin{array}{l}\text { Construção negativa de pais e alunos sobre os/as professores/as serem } \\
\text { homossexuais. }\end{array}$ & 16 \\
\hline (não) aceitação de membro gay nas famílias. & 4 \\
\hline Casais homossexuais podem ser pais de família. & 3 \\
\hline Discriminação contra homossexuais. & 1 \\
\hline Racismo - 15\% & 14 \\
\hline $\begin{array}{l}\text { Pode ser perpetuado através da nomeação de cores das coisas do cotidiano (como } \\
\text { lápis). }\end{array}$ & 10 \\
\hline Pele clara e cabelo liso são considerados melhores. & 4 \\
\hline Família - 13\% & 12 \\
\hline Adultos protegem as crianças de realidades difíceis, mas não deveriam. & 8 \\
\hline Suposições conservadoras sobre estrutura familiar. & 3 \\
\hline Circunstâncias familiares moldam o desenvolvimento das crianças. & 1 \\
\hline Momento Crítico - $12 \%$ & 11 \\
\hline Confiança no livro para definição oficial. & 4 \\
\hline Momentos inesperados que causam reflexão. & 4 \\
\hline $\begin{array}{l}\text { Críticas sobre o livro/material didático ou dos/as professores/as podem gerar } \\
\text { reflexões. }\end{array}$ & 3 \\
\hline
\end{tabular}

Fonte: acervo da autora.

O procedimento de codificação dos dados nos possibilitou identificar os principais conceitos mobilizados pelos/as professores/as em formação, que, durante o projeto, davam sentido à criação do conceito de ensino crítico de LIC, quais sejam: o conceito de momento crítico $(12 \%)$, conceitos relacionados as suas realidades socioculturais, como LGBTQ+ $(26 \%)$, racismo (15\%) e família (13\%), e o próprio conceito de agir docente 
(34\%). No que diz respeito à fonte dos conceitos em desenvolvimento neste contexto de formação docente, outro foco da codificação dos dados, elaboramos o seguinte quadro:

Quadro 2 - Fonte conceitual

\begin{tabular}{|l|c|}
\hline \multicolumn{1}{|c|}{ FONTE DO DESENVOLVIMENTO CONCEITUAL } & Ocorrências \\
\hline Científico - 14.2\% & $\mathbf{2 0}$ \\
\hline Material didático & 12 \\
\hline Pesquisas & 6 \\
\hline Políticas educacionais & $\mathbf{2}$ \\
\hline Espontâneo-Científico - 39.0\% & $\mathbf{5 5}$ \\
\hline Conhecimento sobre o mundo & 31 \\
\hline Projeto - discussões anteriores confirmar/questionar/rever conceito anterior & 14 \\
\hline Momento crítico durante prática docente & 5 \\
\hline Crenças dos/as professores/as & 5 \\
\hline Espontâneo - 46.8\% & $\mathbf{6 6}$ \\
\hline Experiência como professor & 43 \\
\hline Apropriação cultural de estereótipos negativos & 5 \\
\hline Experiência como aluno & 5 \\
\hline Exemplo da prática de outros/as professores/as & 4 \\
\hline Experiência familiar & 4 \\
\hline Conhecimento prévio dos alunos & 3 \\
\hline Opinião dos colegas & 2 \\
\hline
\end{tabular}

Fonte: acervo da autora.

Como podemos observar, os conceitos mais utilizados eram espontâneos ou espontâneo-científicos. Juntos, eles representam quase $86 \%$ de toda a fonte de discussão. Portanto, os/as professores/as em formação recorreram principalmente a suas próprias experiências diárias e pessoais, do que aos livros didáticos ou dados científicos.

Em relação à análise linguístico-discursiva dos dados, ela foi realizada por meio da teoria da argumentação. A proposta de Liberali (2013) é uma perspectiva dialógica e interdependente, porém organizada em categorias, a saber: características enunciativas, discursivas e linguísticas.

Após o trabalho de recorte e organização dos dados, apoio-me nas características discursivas e linguísticas para o desenvolvimento da minha análise. As características discursivas da argumentação:

"[...] são compreendidas a partir de quatro aspectos centrais com relação ao modo como o texto pode ser disposto: 1) o plano organizacional; 2) a organização temática; 3) o foco sequencial e; 4) a articulação entre as ideias apresentadas" (LIBERALI, 2013, p. 66).

O plano organizacional compreende como o enunciado se inicia, desenvolve e encerra (LIBERALI, 2013; LIBERALI; FUGA, 2014). É importante constatar como os 
interactantes iniciam o diálogo, pois isso pode "decidir o tipo de relação que será a base para o desenvolvimento da reunião" (LIBERALI, 2013, p. 66).

No que se refere à organização temática, a investigação se ocupa com o tema, se o que foi proposto é ou não pertinente, se obteve continuidade ou não, por meio das dimensões: desenvolvimento e pertinência.

Liberali (2013) explica que a dimensão do desenvolvimento está relacionada ao avanço na definição do objeto proposto, por meio de uma participação coletiva, com introdução e discussão de novas perspectivas. Enquanto o não-desenvolvimento, como 0 nome propõe, refere-se ao "bloqueio ou interrupção do processo de construção das ideias pelo enunciador ou grupo" (LIBERALI, 2013, p. 67). Já "a dimensão de pertinência oferece base para a percepção se o tema proposto foi seguido ou desviado, comprometendo a progressão (ou não) do discurso" (LIBERALI, 2013, p. 67).

O foco sequencial, segundo Liberali (2013), está relacionado à escolha do tema em discussão. Por esta razão, esta categoria discursiva foi abordada já na seleção e também no recorte dos dados, visto que os excertos analisados possuem a mesma temática: entendimentos e tentativas de ensino crítico de LIC. Assim, não houve, na análise dos dados, relatos utilitários e instrucionais (LIBERALI, 2013), como avisos, cobranças, compartilhamento de materiais, etc., que também faziam parte das discussões do grupo.

No entanto, Liberali (2013) explica que a tematização pode "assumir um caráter mais prático e voltado ao conhecimento cotidiano ou mais teórico e/ou científico" (VYGOTSKY, 2001 apud LIBERALI, 2013, p. 68).Observarei, portanto, segundo o foco sequencial proposto por Liberali (2013), se os efeitos de sentidos causados nos/pelos interlocutores são de origem conceitual prático/cotidiano ou teórico/científico.

Por fim, a articulação discursiva argumentativa se ocupa da "forma como ideias, posições, pontos de vista são apresentados, contrastados, sustentados, acordados" (LIBERALI, 20013, p. 68). Tais funções são organizadas em 13 categorias: 1) abertura do tema ou exórdio; 2) questão controversa; 3) apresentação de pontos de vista/tese; 4) espelhamento, recolocação do que foi apresentado; 5) espelhamento com pedido de dis/concordância; 6) concordância com ponto de vista; 7) discordância/contestação do ponto de vista; 8) negação/ refutação de argumento; 9) acordo ou síntese; 10) pedido/ apresentação de esclarecimento; 11) pedido/ apresentação de contra-argumentação; 12) 
questões para entrelaçamento de falas, modos de questionar; 13) pedido, apresentação de sustentação (LIBERALI, 2013, p. 68).

As características linguísticas da argumentação, por sua vez, estão organizadas em oito mecanismos linguísticos, quais sejam: 1) Mecanismos conversacionais; 2) Mecanismos de coesão verbal; 3) Mecanismos lexicais; 4) Mecanismos de coesão nominal; 5) Mecanismos de valoração; 6) Mecanismos de distribuição das vozes; 7) Mecanismos de modalização; 8) Mecanismos de interrogação. Liberali (2013) denomina esses mecanismos de composição do discurso como "aspectos da materialidade do texto".

Tendo explicitado os procedimentos analíticos, no tópico adiante discutirei os resultados obtidos. Para isso, apresentarei excertos das transcrições, suas análises, códigos e subcódigos mapeados colaborativamente.

\section{Discussão dos Resultados}

As irmãs Joana e Isabel, que se consideravam feministas (participavam de organizações e eventos, como o Encontro de Mulheres Estudantes - EME) e durante os encontros do projeto, discutiam e defendiam os direitos das mulheres. Assim, a fala que será analisada representa um momento crítico relacionado ao feminismo, quando trabalhado por elas:

1. Datado em 26 de abril de 2016

377. Joana - Um exemplo que a Isabel dá, porque a Isabel agora está ficando no corredor. Aí, esses dias atrás, [...] um menininho foi lá e cortou o dedo, machucou, sei lá [...]. E o menininho abriu a boca, fez o maior escândalo e tudo o mais, e tinha uma menininha do lado, aí, o que a Isabel falou pra ele? Você tem que aguentar igual a uma menina, para de chorar desse jeito. Aí, olhou pra menina do lado e falou assim "Não é verdade?", aí ela falou assim "É verdade, eu aguento" [...] Aí, ele foi engolindo o choro, engolindo o choro até parar, porque é lógico, mulher sempre aguentou mais dor do que homem, é lógico isso, eu não sei de onde que as pessoas falam que homem chora igual menininha, entende?

A maneira com que Joana descreve a situação vivenciada por sua irmã mostra seu posicionamento ideológico em relação ao feminismo e a sua identidade de mulher. Para explicar a reação do garoto ao se machucar, ela faz uso de metáforas e mecanismos de valoração (o menininho abriu a boca, fez o maior escândalo e tudo o mais; ele foi engolindo o choro, engolindo o choro, até parar) que representam sua opinião. Por outro lado, ao contar como reagiu a garota, Joana é mais objetiva: "É verdade, eu aguento". É 
possível, então, reafirmar a premissa que discursos são parciais e ideológicos, neste caso, até mesmo de maneira consciente.

Joana narra, através do espelhamento da fala de Isabel e das crianças envolvidas, uma situação vivida pela irmã, cujo foco sequencial é cotidiano e considerado, por ela, como uma ação feminista. Isabel poderia ter apenas cuidado do menino e o ajudado a se sentir melhor, no entanto, ela transformou aquela situação em um momento crítico, uma vez que aproveitou a oportunidade para reformular um pressuposto social de que as mulheres ou garotas são mais fracas do que os homens e garotos.

No entanto, ao fazer isso, ela criou outro pressuposto: o de que as mulheres são mais fortes. Este foi o momento em que interferi, fazendo uso de mecanismos de troca de turno (LIBERALI, 2013), criando um momento crítico em nossa reunião:

2. Datado em 26 de abril de 2016.

378. Déborah - Mas, olha só, Joana! Mas, Joana, olha só! A ideia da Isabel foi brilhante, porque sempre tem esse discurso machista de que se o João é homem tá chorando "Nossa, João, você tá parecendo uma menina!", Okay, mas por outro lado, falar pro João, se ele tiver chorando "Para de chorar e seja forte que nem uma menina", também é preconceituoso, porque você tá menosprezando o homem em relação à mulher.

Nesta situação, eu estava contribuindo com a reformulação do ponto de vista da Joana sobre a força das mulheres e dos homens, a partir da negação/contestação do ponto de vista (LIBERALI, 2013), mas sem um pedido ou apresentação de esclarecimento, isto é, apenas apresentei um ponto de vista contrário, sem propor uma questão controversa capaz de instigar maiores reflexões.

Eu poderia, por exemplo, ter concordado com ela de que é injusto e equivocado dizer que um menino que chora é fraco como uma garota. No entanto, involuntariamente, eu criei a oportunidade de fazer com que todos nós refletíssemos sobre aquilo e o fato de que as pessoas sentem dor de formas distintas, e não de acordo com seu gênero. Este comentário suscitou a seguinte conversa:

3. Datado em 26 de abril de 2016.

379. Joana - Pode ser, pode ser.

380. Déborah - Quando a gente é muito feminista, a gente acaba correndo o risco de...

381. Joana - De ser feminista, tudo bem, isso é fato.

382. João - É, tá vendo que é difícil pensar criticamente, digamos.

383. Déborah - É muito difícil!

384. João - Tem esses detalhes.

385. Joana - Mas como a mulher aguenta é interessante falar isso. 
386. Déborah - Tá, mas a mulher aguenta segundo quem? Tá cientificamente comprovado?

387. Joana - Tem bastante artigo.

388. João - Tá vendo como é difícil.

389. Déborah - É muito difícil!

390. João - Até, digamos assim, como pessoa.

391. Déborah - Exato!

392. João - Eu estou aprendendo a ser crítico. E eu não sou crítico.

Ao refletirmos sobre esta situação, João e eu fizemos uso dos mecanismos de valoração: é muito difícil, como é difícil, para enfatizarmos que o processo de construção conceitual do ensino crítico de LIC é complexo e árduo.

A minha prática argumentativa é realizada por meio da metáfora, corremos o risco de, que indica a minha maneira de legitimar meu ponto de vista de que é necessário cautela ao rotularmos ideologias, como a feminista.

Joana, então, me interrompe usando um mecanismo de coesão nominal, para retomar seu entendimento de que ser muito feminista é ser feminista, não permitindo diferentes noções do feminismo. Mecanismos de coesão nominal são importantes para "o estabelecimento de relação entre falas e colocações dos diferentes interlocutores" (LIBERALI, 2013, p. 77). Neste caso, a retomada de turno de Joana é sua chance de reforçar sua posição sobre o debate, legitimada pelo seu tom enfático: isso é fato.

Certamente a opinião de Joana sobre este episódio havia sido formada depois de ter percebido a reincidência de expressões como "chorar como uma menininha". Como mulher, já foi uma menina e está em seu lugar de fala para expressar: eu não sei de onde que as pessoas falam que homem chora igual menininha. $O$ diminutivo da palavra menina já enaltece um tom pejorativo e o entendimento de Joana já indica um movimento de reação feminista.

Este excerto representa o momento crítico que ocorreu durante o projeto e não nas aulas dos/as professores/as em formação, como nas demais unidades de análise. Desta vez, eu fiz referência a minha própria interpretação do evento para discutir meu ponto de vista e questionei, fazendo menção ao conhecimento acadêmico formal: segundo quem? Tá cientificamente comprovado?

Joana, por sua vez, mantinha seu ponto de vista baseado no senso comum e em sua própria opinião (conceitos espontâneos) de que mulheres são mais fortes que homens: mulher sempre aguentou mais dor do que homem; e o argumenta por meio da repetição dos mecanismos de valoração: porque é lógico; é lógico isso. Apesar de 
mencionar a existência de artigos científicos que comprovassem tal premissa, não os apresentou, nem mesmo no outro encontro subsequente, possivelmente fez tal menção apenas para responder ao meu questionamento.

O momento crítico levantado, aqui, foi bastante complexo, a ponto de haver uma interrupção do assunto. Segundo as características discursivas, o não-desenvolvimento da temática é caracterizado como uma situação de inércia (LIBERALI, 2013), em contrapartida, este momento crítico foi retomado em outra reunião:

4. Datado em 10 de maio de 2016.

455. Joana - Mas, lembra do que você disse? Que nem a Isabel fez, que o menininho estava chorando, [...] tinha acontecido alguma coisa com ele, aí, uma menininha estava do lado. A Isabel chegou no menininho e falou assim "Não chora, não, faz igual as meninas", ah, nem lembro direito agora, faz tempo. Falou assim "Se comporta como uma menina, as meninas não choram, aguenta igual a uma menina". Aí, ela perguntou pra menininha "Não é verdade que menina aguenta mais dor?". Aí, a menina deu risada e falou "É verdade, você não tá aguentando nada". Entendeu? Tipo, porque, realmente, menina aguenta mais dor.

456. Nicolas - Sempre fala, né? "Chora que nem uma menininha".

457. Joana - Tá chorando igual a uma menininha, eles falam, e o certo é...

458. Déborah - Seja forte como uma menina.

459. Joana - Seja forte como uma menininha, mas aí, igual, tipo, a Déborah falou da outra vez, ela falou, é...mas a gente tá falando a nossa ideia de que menino é forte, na realidade, os dois são humanos, são iguais. $E$ a gente impôs a nossa opinião, foi crítico, mas impôs a opinião, que é forte.

Neste excerto, é possível observar as "diversas vozes [que] lutam na enunciação" (LIBERALI, 2013, p. 42) de Joana: a fala de Isabel, da menina, do senso comum e a minha. Ao basear-se em Bakhtin (1934-35/1998), Liberali (2013) defende que somos circundados por múltiplas vozes, por isso a linguagem é social e não individual.

O conceito de força construído em relação aos gêneros masculino e feminino foi sendo moldado por Joana por meio das palavras e experiências de outrem. Da mesma forma que as práticas argumentativas de Joana e Nicolas exemplificam a assimilação dos discursos de outros (Liberali, 2013). Os dois professores em formação afirmam: sempre fala; eles falam, referindo-se ao senso comum sobre o que é ser forte e/ou sobre quem chora mais.

Joana levantou esta situação novamente e repetiu, como no encontro de 26 de abril, que realmente, menina aguenta mais dor, desta vez, no entanto, ela acrescentou: meninos e meninas são iguais. Segundo as características discursivas desta análise, o modo de articulação de Joana representa a busca por um acordo em sua própria fala, ao 
tentar "encontrar nova posição que aglutine diferentes posicionamentos a partir de concessões" (LIBERALI, 2013, p. 69).

Para concluir seu argumento, Joana traz novamente a minha voz: a Déborah falou da outra vez, ela falou, e uma voz coletiva que possivelmente se refere a dela e de sua irmã, Isabel: a gente tá falando; a gente impôs a nossa opinião. O compartilhamento deste momento crítico no projeto e a reflexão sobre ele, através de diferentes pontos de vista, resultaram na mudança de pressupostos acerca do que é ser/agir criticamente, por meio de ações a não serem tomadas (impor opinião), bem como a generalização da força da mulher em relação ao homem, da mesma maneira que seu questionamento inicial direcionado para mim, mas, lembra do que você disse, é uma forma de recolocação do que já havia sido apresentado (LIBERALI, 2013). Por isso, é possível entender que o momento crítico, enfrentado anteriormente e trazido novamente para o projeto, culminou no reframing empático da opinião sobre garotos e garotas serem iguais ou não. Por outro lado, suas dúvidas produziram certa ambivalência sobre a igualdade entre mulheres e homens e a capacidade de lidar com a dor.

A retomada, portanto, a continuação do desenvolvimento desta organização temática (LIBERALI, 2013) permite apontar a fonte conceitual espontâneo-científica (com 39\% de ocorrência) identificada no processo de codificação colaborativa dos dados . Noutras palavras, as práticas argumentativas mantidas nos encontros do projeto contribuíam com o desenvolvimento conceitual dos participantes.

Outra consequência deste momento crítico é percebida quando ela menciona que sua irmã impôs suas ideias, direcionando a discussão para reflexão sobre a imposição de ideias como um fator acrítico. Joana diz: a gente impôs a nossa opinião, foi crítico, mas impôs a opinião. Aqui, a professora em formação expressa seu sentido do que é crítico a partir do que não é ou não se deve fazer para ser crítico. Fica evidente seu posicionamento de que impor a opinião é agir de maneira não crítica.

As conexões realizadas nesta fase passam a ser não apenas positivas, mas também negativas, isto é, aquilo que se encaixa ou não no todo (VYGOTSKY, 2008) que, segundo Vygotsky (2008), indicam um pensamento complexo (e não conceitual). Este traço comum, em contrapartida, é instável, visto que "não ocupa uma posição privilegiada e facilmente cede o seu domínio temporário a outros traços" (VYGOSTKY, 2008, p. 98). Os/as professores/as em formação utilizarão outras conexões para desenvolver o conceito de ensino crítico de LIC, e o conceito propriamente dito surgirá 
somente quando os traços forem reestabelecidos e se tornarem o principal instrumento do pensamento (VYGOTSKY, 2008).

O excerto adiante representa momentos críticos em relação à preocupação dos/as professores/as quanto à reformulação dos conceitos dos estudantes sobre tipos de cabelos e cor de pele. Eu havia questionado se eles já haviam enfrentando algum momento crítico.

A partir dessa provocação, mencionam a brincadeira "elefante colorido", a qual é jogada seguindo uma única regra: as crianças devem tocar algo que possui a cor dita de maneira rápida. Neste contexto, os/as professores/as faziam uso do jogo para ensinar as cores em inglês. Quando alguém gritava a cor "cor de pele", em português, visto que não há uma equivalência em inglês, as crianças costumavam tocar a si mesmas, no entanto, não tocavam em outras crianças negras, pois "cor de pele" usualmente refere-se ao lápis de cor rosa claro. Assim, as crianças não reconhecem "cor de pele" como qualquer outra cor de pele.

5. Datado em 19 de abril de 2016.

783. João - Aí eles tão, por exemplo, pintando alguma coisa, aí fala: "alguém tem cor de pele?" eu chego na criança: o que que é cor de pele? 784. Joana - Ai eu fiz isso.

785. João - Ai isso daqui, ó, isso é cor de pele (apontando para a própria pele). Ai isso daqui, ó, isso é cor de pele (apontando para a pele do colega). Essa cor é igual a minha? Aí...

786. Joana - Isso foi muito legal, Elefante Colorido é a melhor coisa pra brincar disso...

787. João - Eu faço muito isso.

788. Joana - Elefante Colorido aí, que cor? Aí fala em inglês a corzinha, né?! Aí cor de pele nunca saiu em inglês, eles sempre falam em português, enfim. Aí relaram numa menininha branquinha e uma menina relou em mim, aí eu relei em mim, porque é a primeira coisa que a gente rela, aí eu vi que tinha uma menina negra, aí eu fui lá correndo e relei na menina negra, só pra ver o que eles iam fazer, aí: "não teacher, não é cor de pele", eu falei assim: é a cor da pele, como não é cor de pele? Aí eles: "aaah".

789. João - Mas as professoras ensinam desde o comecinho.

790. Joana - Claro!

791. Nicolas - É que nem um dia também, uma aluna minha ela tinha cabelo bem enroladinho, aí o povo falava assim: "A Sofia tem o cabelo ruim" falei: o que é ter um cabelo ruim? É um cabelo que bate no povo? É um cabelo que rouba? É um cabelo que, sabe?

(Risos)

792. Déborah - Muito bom!

793. Nicolas - Aí eles falam assim: "não é..." eu falei: gente, cabelo é cabelo, cabelo é liso, cabelo enrolado, cabelo, cabelo, cabelo, não existe cabelo ruim. Aí eles pensaram. 
Primeiramente, se retomada a codificação colaborativa dos dados, é possível identificar a fonte conceitual espontâneo-científica (39\%), como base para esta prática argumentativa, por meio do subcódigo dos conceitos em uso, a saber: racismo (15\% de ocorrência) e o conceito de momento crítico (12\%).

O conceito de agir docente (34\%) também está presente por meio do subcódigo professores podem prevenir ou perpetuar estereótipos e intolerância, evidenciado na fala de João: as professoras ensinam desde o comecinho (os alunos a se referirem ao lápis de cor rosa claro como cor de pele), em que Joana, imediatamente, concordou: Claro! Esse posicionamento de João, reforçado por Joana, reafirma o sentido gradual e social do desenvolvimento de conceitos. Isto é, as crianças não nascem nomeando cores, mas elas são ensinadas a fazer isto. É possível inferir também que mesmo se tratando de um processo que pode ser inconsciente, neste caso, os/as professores/as em formação sabem da influência da educação, no papel dos/as professores/as e no desenvolvimento de conceitos das crianças.

O turno de João é iniciado com o relato de um momento crítico que aconteceu durante sua aula. Ao solicitar um lápis "cor de pele" emprestado, a criança teve a oportunidade de refletir sobre isso. Assim como os/as alunos/as de Joana, que relatou ter feito uso da brincadeira "elefante colorido" como uma estratégia para reconstruir o conceito de cor de pele.

Ainda que as gravações dos encontros tenham sido apenas de áudio, algumas manifestações corporais foram descritas durante o processo de transcrição e leitura inicial dos dados. Neste excerto, por exemplo, João contra evidencia o entendimento do que vem a ser cor de pele por seus/suas alunos/as por meio da apresentação da sua própria cor de pele (negra). Ele exemplifica no projeto o que diz ter feito em sala de aula: Ai isso daqui, ó, isso é cor de pele (apontando para a própria pele). Ai isso daqui, ó, isso é cor de pele (apontando para a pele do colega). Essa cor é igual a minha? Aí...

Depreende-se daí a importância da discussão sobre representatividade, políticas de inclusão e permanência, lugar de fala e um grupo formado por sujeitos pertencentes a realidades socioculturais bastante diferenciadas. João é o único membro do grupo capaz de discutir preconceito racial como personagem principal, representado pela simplicidade em apontar para o próprio corpo com o intuito de suscitar reflexões.

Nicolas, por sua vez, mantém o desenvolvimento da temática acerca dos momentos críticos, indicando a pertinência deste tópico (LIBERALI, 2013) e exemplifica 
narrando uma situação em que ajudou seus/suas alunos/as a reformularem a ideia de fazer uso de adjetivos positivos e negativos para cabelos que são apenas diferentes. Seu objetivo era mudar o entendimento de que cabelos encaracolados são "ruins", uma vez que esta concepção só existe devido ao racismo estrutural em nossa sociedade.

Da mesma maneira que Nicolas fez uso de mecanismos de valoração (o emprego de adjetivos e verbos socialmente valorizados como positivos e negativos: ruim; bater; roubar), meu feedback, indício da minha identidade de professora ao seu testemunho, também caracterizado como um mecanismo de valoração por meio da expressão intensificadora: muito bom!

Ainda que os/as professores/as em formação tenham imposto a sua visão às crianças, tais relatos podem ser considerados momentos críticos, pela espontaneidade. Esta reflexão está diretamente relacionada ao reframing empático, uma vez que João e Nicolas buscavam uma reformulação sobre as questões de cor e raça, que seus alunos não alcançariam sem esse auxílio.

As crianças eram acostumadas a relacionarem o cabelo encaracolado a cabelo "ruim", e cor de pele ao lápis rosa claro, pois não tiveram a oportunidade de refletir de maneira diferente, de desenvolver empatia com as pessoas que possuem traços físicos diferentes. Por esta razão, esta foi uma oportunidade para os/as professores/as transformarem as construções sociais sobre tipos de cabelo e tons de pele.

Os/as professores/as em formação revelam uma preocupação com o processo de ensino-aprendizagem por meio de perspectivas críticas primeiramente pela disposição em se unir ao projeto com este foco. Essa participação representa também o entendimento de que:

"[...] para conseguir que os alunos se apropriem do saber escolar de modo a se tornarem autônomos e críticos, o professor precisa estar, ele próprio, apropriando-se desse saber e tornando-se cada vez mais autônomo e crítico" (MAZZEU, 1998, p. 2).

Podemos perceber isto, na autonomia e criticidade que foram legitimadas durante a participação no projeto. O reflexo da (difícil) realidade desses professores em formação é evidente em suas práticas docentes, bem como nos dados desta pesquisa.

No excerto a seguir, havíamos baseado nosso encontro em um artigo que fala sobre a abordagem de uma professora de inglês, como primeira língua, da primeira série em um contexto rural nos EUA, Kim, a qual decidiu contar para seus alunos histórias de questões sociais complexas, como The lady in the box (MCGOVERN, 1997). Seu objetivo 
era desenvolver letramento crítico ao ajudar seus alunos a se identificarem com aquelas realidades e aprenderem a ler além das entrelinhas. No final, ela conseguiu notar uma melhora na escrita das crianças e na empatia com os outros.

O início do excerto é marcado pela minha fala, caracterizada como uma articulação discursiva de espelhamento, visto que trago a voz da autora do artigo, identificada como uma fonte conceitual científica, para o projeto:

6. Datado em 07 de junho de 2016.

52. Déborah - Porque esse artigo, ela conta a história dela, e eu fiquei com muita vontade de fazer o que ela fez, por que a ideia dela é assim, eu até trouxe o livro pra você e pra Joana, não é contar essas histórias de criança que tem final feliz, todos os livrinhos de criança são assim, ela pegou a história de tristeza, tragédia, assim, sabe? Tipo, uma história, inclusive, é a mulher que morava numa caixa de papelão, então, conta a história de gente de rua, gente drogada, gente traficante, essas coisas. $\mathrm{E}$ aí, a ideia dela é isso, mostrar pra essas crianças que a literatura, tal, faz sentido com a realidade delas, porque "Ai, todo mundo é feliz".

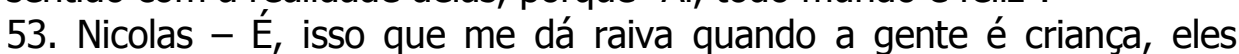
escondem as coisas da gente, entendeu? Eu acho que a gente vai escondendo, escondendo, escondendo, quando o mundo dá um tapa na sua cara "Ó, como que é o mundo", a gente vê que assusta e tal. Então, eu acho que desde pequeno, a gente tem que trabalhar com as crianças de como é, que nem, eu trabalho diversidade com elas, entendeu? Porque não ficar naquela mesma... que nem "Ai, ser gay é ruim.", esses dia, o povo estava falando na sala que quem tem brinco é gay, eu falei "E se for? Qual é o problema?".

54. Isabel - deixa eu vou contar isso aí do menino, eu estava lendo a história pra eles do João e o pé de feijão, aí, ele falou assim "Professora, a minha tia se veste de homem, ela não gosta de se vestir de mulher". Ai, eu "Mas, se ela é feliz assim, né? Deixa ela se vestir do jeito que ela quiser, né? Você também quando crescer, você pode se vestir de mulher, de homem, tanto faz, o importante é você estar feliz, ninguém tem nada a ver com a sua vida". Aí, ele ficou feliz. Aí, depois eu contei na direção essa história, aí, o menino [professor estagiário] falou assim: "Nossa, isso é muito difícil, né? Você ter que falar essas coisas, mesmo não acreditando. Ai, isso é tão difícil, essa política que faz você ter que falar essas coisas para as crianças". Eu falei assim "Mas eu acredito nisso! Ninguém tem nada a ver com a vida dela", aí, ele falou assim "Homem tem que se vestir de homem e mulher tem que se vestir de mulher". Gente! Não, mas, pelo menos, respeita e fala, o que as políticas falam.

Nesta conversa, estávamos discutindo histórias que poderiam ser contadas em sala de aula. Ao basear-me em conceitos científicos (que representam 14,2\% da fonte conceitual), a partir do artigo, eu sugeri que contássemos histórias que retratassem as lutas da vida real. Novamente, os/as professores/as em formação serviram-se de suas próprias realidades, conceitos espontâneos (46.8\% da fonte conceitual). Nicolas e Isabel 
compartilharam momentos críticos, visto que foram eventos que ocorrerem em sala de aula, que não foram planejados e oportunizaram reflexão.

Enquanto Nicolas estava preocupado com o preconceito que homossexuais sofrem, por já ter experienciado isso, Isabel compartilhou sua história sobre ser desrespeitada pela maneira como se veste, fato que ela própria também já viveu, como conhecimento espontâneo, quando sua família acreditava que ela era homossexual devido a sua aparência.

A professora em formação também se reporta às políticas públicas para manter o desenvolvimento do tema, porém altera o foco sequencial (LIBERALI, 2013) para um caráter mais científico. Através do trecho: Mas eu acredito nisso! Ninguém tem nada a ver com a vida dela, identifico ênfase da fala de Isabel em concordância com as políticas mencionas (ainda que não explicadas) por ela.

As pessoas representam, refletem e podem desenvolver o processo de reframing empático a partir daquilo que elas já vivenciaram, por meio de conhecimentos espontâneos. Assim, é possível identificar a união entre representatividade e a disposição em contribuir com a redução do sofrimento e do preconceito.

Como professores/as e pesquisadores/as, isso nos mostra a importância da criação de sentidos a partir das subjetividades com relação aos conceitos científicos. Enquanto seres humanos somos afetados por aquilo que atravessa nossas identidades, corpos, raças, cores, por isso, as vivências e condições sociais possuem um papel significativo no desenvolvimento conceitual e também acadêmico e profissional.

Tanto eu, quanto Nicolas e Isabel fizemos uso da expressão de cunho descritivo de senso comum: essas coisas, que denota traços de generalizações implícitas em nossas falas. Não foi preciso detalhar nossos entendimentos e exemplos para sermos entendidos, o que significa que os ouvintes sabiam ao que nós nos referíamos, ou seja, já havia uma empatia.

Ao continuarem conversando sobre o respeito que pode ser perpetuado e também podado pelos/as professores/as, Nicolas traz a seguinte contribuição:

7. Datado em 07 de junho de 2016.

64. Nicolas - Que nem aquela coisa, gay na família dos outros é bonito [...] Quando é gay na família do outro, todo mundo tá apoiando, agora quando é na sua própria família.

65. Déborah - Exato!

66. Joana - Eu não sei, olha, nossa família foi muito sério, a mãe vivia falando que a Isabel era gay. 
67. Isabel - É, ela vive querendo arrumar namorada pra mim. Namorada. 68. Nicolas - Ah, minha mãe também. Namorado. Eu sou, mas minha mãe fica me enchendo o meu saco "Tem que namorar pra ser feliz, tem que arrumar uma pessoa", que nem agora.

Aqui, é retratado o modo com os/as professores/as que já sofreram algum tipo de preconceito estão conscientes do malefício que podem causar, portanto, preocupados e em busca de ajudar seus/suas alunos/as. Esta é a importância da representatividade: falar a partir das marcas de representações pessoais, a partir de si e não do outro.

Conceitos partem do social para o pessoal. A partir deste excerto, é possível compreender que Isabel não se "encaixa" nos padrões femininos esperados pela/na nossa sociedade. Sua própria mãe a considerava homossexual, pois seu conceito de orientação heterossexual feminino foi culturalmente desenvolvido por uma imposição social de que a mulher "é" (deveria ser) de determinada maneira, e ela não identificava sua filha pertencente a este padrão.

O mecanismo de valoração utilizado por Joana, na nossa família foi muito sério, atribui à opinião da mãe e da família alto grau de relevância em relação à orientação sexual de sua irmã, Isabel. Por outro lado, sua escolha verbal: a mãe vivia falando que a Isabel era gay indica que tal desentendimento não acontece mais. A marca linguística de Isabel, no entanto, se difere: ela vive querendo arrumar namorada pra mim. Desta vez, o tempo verbal denota que a mãe mantém sua crença sobre a filha. Ademais, a professora em formação parece desabafar ao repetir o termo namorada. É relevante destacar, neste excerto, a fonte conceitual espontânea (46.8\% de ocorrência). Além das experiências vivenciadas nos papéis de professores/as e alunos/as, a identidade de filho/a também contribui com o desenvolvimento conceitual.

\section{Conclusão}

Como ilustrado na análise, eu e os/as professores/as em formação tivemos uma conexão empática, ou reframing empático, uns com os outros, com os/as alunos/as e até mesmo com os textos. Ainda que não tenhamos criado um conceito genuíno de ensino crítico de LIC, esta contribuição foi fundamental durante o processo de desenvolvimento conceitual.

É possível notar que a noção de ensino crítico de LIC, enquanto momentos críticos que desencadeiam reframing empático, se encontra no estágio de desenvolvimento de pseudoconceito. A ausência de conceitos científicos pode justificar a fragilidade desta 
abordagem, visto que o próprio Vygotsky defende a formação profícua de um conceito por meio da interação de conceitos espontâneos e científicos, pois:

[p]ara Vygotsky (1934/1987a) os conceitos mais robustos são desenvolvidos através de uma síntese dos dois; na verdade, ele argumenta que nenhum deles é suficiente [individualmente] e que cada um deve ser colocado em diálogo com o outro para que as abstrações façam sentido empírico e que o conhecimento experiencial seja adaptável a novas condições (SMAGORINSKY; JOHNSON, 2017, p. 5, tradução nossa).

A conexão empática que contribuiu com o desenvolvimento de tal entendimento foi experienciada "apenas" na forma de um conhecimento espontâneo. Não houve um diálogo a partir de conceitos científicos, fator que poderia ter dado maior sentido e robustez na trajetória para a construção de um conceito.

Ainda assim, é possível concluir que este contexto de formação inicial de professores/as foi propício para o desenvolvimento do reframing empático tão necessário na construção de uma sociedade mais humana, que pode começar dentro da sala de aula.

\section{Referências}

BRASIL. Ministério da Educação. Conselho Nacional de Educação. Resolução No 7, de 14 de dezembro de 2010. Fixa Diretrizes Curriculares Nacionais para o Ensino fundamental de 9 (nove) anos: Brasília, 2012. Diário oficial da União: seção 1, Brasília, DF, p. 34, 15 dez. 2010. Disponível em: http://portal.mec.gov.br/dmdocuments/rceb007_10.pdf. Acesso em: 17 dez. 2018.

BARDIN, Lawrence. Análise de conteúdo. Tradução de L. de A. Rego \& A. Pinheiro. Lisboa: Edições 70, 2006.

FREIRE, Paulo. Pedagogia do oprimido. 17. ed. Rio de Janeiro: Paz e Terra, 1987.

FREITAS, Marco Túlio de Urzeda; PESSOA, Rosane Rocha. Ensino crítico de línguas estrangeiras/inglês e formação crítica de professores/as: a pedagogia como transgressão. In: REUNIÃO ANUAL DA SOCIEDADE BRASILEIRA PARA O PROGRESSO DA CIÊNCIA SBPC, 63., 2011, Goiânia, GO. Resumos [...]. Goiânia: SBPC, 2011. Disponível em: http://www.sbpcnet.org.br/livro/63ra/conpeex/mestrado/trabalhos-mestrado/mestradomarco-tulio.pdf. Acesso em: 11 jan. 2016.

LIBERALI, Fernanda. Argumentação em contexto escolar. Campinas: Pontes Editores, 2013.

LIBERALI, Fernanda; FUGA, Valdite P. Argumentação na atividade de formação crítica, colaborativa e criativa. In: MATEUS, E.; OLIVEIRA, N. B. De (orgs.). Estudos Críticos da Linguagem e Formação de Professores/as de Línguas: contribuições teóricometodológicas. Campinas: Pontes, 2014. 
MATEUS, Elaine. Ética como prática social de cuidado com o outro: implicações para o trabalho colaborativo. In: MAGALHÃES, Maria Cecília; FIDALGO, Sueli Salles (org.). Questões de método e de linguagem na formação docente. Campinas: Mercado de Letras, 2011, p. 187-209.

MATEUS, Elaine; EL KADRI, Michele; SILVA, Kleber (org.). Experiências de formação de professores de línguas e o PIBID: contornos, cores e matizes. Campinas, SP: Pontes Editores, 2013.

MAZZEU, Francisco José Carvalho. Uma proposta metodológica para a formação continuada de professores na perspectiva histórico-social. Cadernos CEDES, Campinas, SP, v. 19, n. 44, abr. 1998. p. 59-72.

MISSISSIPI STATE UNIVERSITY. Comparative Analysis, guide to freshman composition. 2011. Disponível em:

http://www.english.msstate.edu/comp/compmaterials/2011_Comparative_Analysis.pdf. Acesso em: janeiro de 2017.

MCGOVERN, Ann. The lady in the box. New York: Turtle, 1997.

PENNYCOOK, Alastair. Critical applied linguistics: a critical introduction. Mahwah, NJ: Lawrence Erlbaum, 2001.

PENNYCOOK, Alastair. Critical moments in a TESOL praxicum. In: NORTON, Bonny; TOOHEY, Kelleen. Critical pedagogies and language learning. Cambridge: Cambridge University Press, 2004. p. 327-346.

SMAGORINSKY, Peter. The development of social and practical concepts in learning to teach: A synthesis and extension of Vygotsky's conception. Learning, Culture, and Social Interaction, Oxford, UK, v. 2, n. 4, p. 238-248, 2013. Disponível em:

http://www.petersmagorinsky.net/About/PDF/LCSI/LCSI_2013.PDF. Acesso em: 4 fev. 2017.

SMAGORINSKY, Peter. The method section as conceptual epicenter in constructing social science research reports. Written Communication, Thousand Oaks, CA, v. 25, p. 389-411, 2008.

SMAGORINSKY, Peter; COOK, Leslie Susan; JOHNSON, Tara Star. The twisting path of concept development in learning to teach. Teachers College Record, New York, NY, v. 105, n. 8, p. 1399-1436, 2003. Disponível em: http://www.petersmagorinsky.net/About/PDF/TCR/TCR2003.pdf. Acesso em: 4 fev. 2017.

SMAGORINSKY, Peter; JOHNSON, Lindy L. Empathic reframing of social justice concepts in book club discussions in a service-learning teacher education class. [S. I: S. $n$ ], 2017. In review.

VYGOTSKY, Lev Semyonovich. A construção do pensamento e da linguagem. São Paulo: Martins Fontes, 2008.

VYGOTSKY, Lev Semyonovich. A formação social da mente. São Paulo: Martins Fontes, 2007. 